\title{
A INFLUÊNCIA DA ORIGEM DO CONTROLE ACIONÁRIO NO NÍVEL DE SOCIAL DISCLOSURE EM EMPRESAS BRASILEIRAS
}

\author{
Rodrigo de Souza Gonçalves \\ Doutor em Ciências Contábeis - UnB \\ Professor do Programa Multi-institucional e Inter-regional de Ciências Contábeis - UnB/UFPB/UFRN \\ rgoncalves@unb.br
}

\author{
Alisson Pereira Rodrigues \\ Bacharel em Ciências Contábeis pela Universidade de Brasília \\ alisson.unb@gmail.com \\ Claudio Moreira Santana \\ Mestre em Ciências Contábeis - FEA/USP \\ Professor da Universidade Federal de Goiás - UFG \\ cldsantana@unb.br \\ Andrea de Oliveira Gonçalves \\ Doutorado em Integração da America Latina - USP \\ Professora do Mestrado Profissional em Gestão Pública - UnB/FUP \\ andreagon@unb.br
}

\begin{abstract}
RESUMO
O objetivo deste artigo é analisar se a origem do controle acionário é fator determinante no nível de social disclosure. Para tanto, foram avaliados os níveis de social disclosure, nos anos de 2009, 2010 e 2011, das empresas brasileiras com controle acionário estrangeiro. Para fins de análise, as empresas foram agrupadas em shareholder ou stakeholder, de acordo com La Porta et al. (1998), considerando-se como sede o país controlador. Os resultados encontrados apontam que não há diferenças relevantes e estatisticamente significantes entre os níveis de social disclosure encontrados nos dois grupos. Observase que o aumento da divulgação de informações sociais está atrelado a aspectos que orientam os preparadores na elaboração de seus relatórios, a exemplo do Balanço Social. Além disso, acredita-se que aspectos, tais como a cultura local e a orientação contábil voltada à regulação sejam uma das principais características que determinam o aumento da evidenciação social para as empresas ora analisadas. Por fim, sugere-se para pesquisas futuras a análise do nível de social disclosure, levando-se em consideração outros determinantes da divulgação, além da origem do controle acionário.
\end{abstract}

Palavras-chave: Controle acionário; Nível de social disclosure; Programas sociais.

\section{THE INFLUENCE OF THE ORIGIN OF EQUITY CONTROL IN THE LEVEL OF SOCIAL DISCLOSURE IN BRAZILIAN COMPANIES}

\begin{abstract}
This analysis was carried out by assessing the levels of social disclosure in Brazilian companies with controlled foreign equity for the years 2009, 2010, and 2011. For the purpose of analysis, the companies were grouped into two categories, shareholders or stakeholders, as recommended by La Porta et al. (1998) with the controlling country being regarded as the headquarters. The results obtained suggest that there are no important or statistically significant differences between the levels of social disclosure found in the two groups. It should be noted that the increased disclosure of social information is linked to factors that can guide those responsible for drawing up reports, for example the Social Balance Sheet. In addition, it is believed that factors such as local culture as well as accounting guidelines aimed at greater regulation can be one of the main features that determine the increase of social disclosure for the companies being analyzed here. Finally, it is suggested that in carrying out further research regarding the level of social disclosure, other determinants of disclosure, as well as the origins of equity control should be taken into account.
\end{abstract}

Key words: Equity control; Social disclosure level; Social programs. 


\section{INTRODUÇÃO}

A partir da década de 1980 e, principalmente, nas décadas seguintes (1990 e 2000), com as reformas econômicas, o Plano Real e as mudanças na legislação, o Brasil passou a receber mais recursos estrangeiros (Soihet, 2002). Além disso, a entrada desses recursos no país foi impulsionada pela estabilização da economia e pela queda de juros internacionais, promovendo a sofisticação e o maior desenvolvimento do mercado de capitais brasileiro.

Segundo dados do Banco Central do Brasil (2011), o volume de investimentos estrangeiros diretos ingressados no país aumentou de US\$ 20,26 bilhões em 2004 para US\$ 33,70 bilhões em 2007. Como resultado desse crescimento, houve uma maior presença de empresas com controle acionário externo no país, bem como a troca de controle, antes predominantemente nacional com gestão familiar, pelo controle estrangeiro (Vieira \& Mendes, 2006). Segundo Braga et al. (2011), essa mudança na estrutura organizacional trouxe consigo a influência de aspectos legais, comportamentais e culturais de outros países.

Com isso, o desenvolvimento de práticas de governança corporativa tornou-se necessário, pois, segundo Rogers (2006), resulta em um aumento da liquidez das empresas, do volume e de negociação e de seu valor de mercado e, ainda, propicia a redução de volatilidade de suas ações. Além disso, essas práticas podem assegurar maior proteção aos investidores minoritários e melhor transparência das informações (Silveira, 2002; Rogers, 2006; Camargos \& Romero, 2006).

Choi e Meek (2008) abordam que o crescimento do mercado de capitais atrai investidores individuais e impulsiona as entidades a melhorarem suas práticas de divulgação. Com isso, a busca por um melhor disclosure pode levar as organizações a oferecerem informações adicionais, como, por exemplo, as ações de responsabilidade social.

Segundo Jones (1999), a responsabilidade social traz benefícios para a empresa em longo prazo, incluindo-se os de natureza econômica. Sob esse prisma, autores, tais como Baron (2001) e Heal (2004) entendem que essas ações, quando realizadas na sociedade, podem diminuir o denominado custo de transação e gerar consequentes benefícios à imagem organizacional.

Em consequência do envolvimento da empresa com a sociedade, em razão das ações de responsabilidade social corporativa, torna-se relevante, entre outros fatores, segundo Machado (2010) o papel da comunicação, e, neste contexto, o social disclosure poderá servir como instrumento de divulgação das ações empresariais e sua repercussão ocorrerá na comunidade em que a empresa está instalada.

Entre outras informações, o social disclosure esclarece ao investidor os motivos que levaram a empresa a investir em programas sociais, inclusive como os recursos investidos estão sendo gastos nesses, suas metas, seus objetivos e os resultados alcançados.

Contudo, em razão das diferentes prioridades na divulgação de suas informações aos mais diversos usuários (shareholders e stakeholders), o modo como essas são produzidas pode ser diferente de acordo com o país de origem que exerce controle sobre a organização. Diante disso, a origem do país controlador influencia no nível de social disclosure das ações realizadas em programas sociais externos?

Para tanto, esta pesquisa tem como objetivo geral analisar se a origem do controle acionário é fator determinante no nível de social disclosure. Como objetivos específicos, têm-se: (a) identificar se a empresa teve no período analisado ações de responsabilidade social externas; (b) avaliar o nível de social disclosure e suas características; (c) identificar o controle da organização; e (d) classificá-las a partir de seu país de origem.

Esta pesquisa é relevante na medida em que contribui para a discussão acerca dos fatores/determinantes que podem influenciar no nível de social disclosure nas empresas brasileiras, tendo como ponto de partida a segregação por país/grupo de origem. Destaca-se que os estudos dessa temática centraram-se, até o momento, em analisar os determinantes da evidenciação social considerando outras variáveis, tais como tamanho, listagem em bolsas internacionais, alavancagem, setor, entre outros (v.g., Riahi-Belkaoui \& Karpik, 1988; Gray et al., 2001; Richardson \& Welker, 
2001; Campbell, Moore \& Shrives, 2006; Clarkson et al., 2008; Reverte, 2008; Branco \& Rodrigues, 2008; Simnett, Vanstraelen \& Chua, 2009; Murcia \& Santos, 2009; Chih, Chih \& Chen, 2010; Gamerschlag, Moeller \& Verbeeten, 2011).

Dessa forma, tem-se como hipótese central do estudo que subsidiárias brasileiras cujo país de origem privilegie os interesses dos stakeholders poderão ter um maior nível de social disclosure (Roberts, 1992; Simnett, Vanstraelen \& Chua, 2009) $-\mathrm{H}_{1}$, ou ainda, em razão da difusão e relevância dessa informação, essa origem pode não ter influência alguma $-\mathrm{H}_{0}$.

Este estudo está estruturado da seguinte forma, além desta introdução, a segunda parte discorre acerca da fundamentação teórica, que discute aspectos relacionados à responsabilidade social nas organizações e ao social disclosure. O terceiro tópico trata da metodologia utilizada no trabalho, o quarto tópico analisa e discute os resultados e, por fim, a quinta parte evidencia os aspectos conclusivos do estudo.

\section{REFERENCIAL TEÓRICO}

Pesquisas relacionadas à responsabilidade social das organizações vêm ocorrendo de modo mais intenso, pelo menos, há cerca de cinco décadas (Cochran \& Wood, 1984). Desde então, os estudos que cercam essa temática concentram-se em debater aspectos relacionados desde ao próprio conceito de responsabilidade social aplicado às organizações com fins lucrativos até o meio, a forma e o que divulgar às partes interessadas (stakeholders).

Autores, tais como Friedman (1970), Sternberg (1999) e Jensen (2001) entendem que a responsabilidade social corporativa restringe-se ao aspecto operacional, isto é, à finalidade para a qual as empresas foram constituídas, buscando maximizar o resultado para o acionista, o que, consequentemente, estaria maximizando o resultado para toda a sociedade.

Com base nessa linha de raciocínio, as empresas não deveriam realizar ações discricionárias de responsabilidade social, sobretudo alocando recursos em programas sociais ${ }^{\mathrm{i}}$, que não são convergentes com os propósitos para os quais foram constituídas. Nesse sentido, Brigham, Gapenski e Ehrhard (2001) entendem que os gestores poderão alocar recursos em atividades não atrativas, como é o caso dos programas sociais, e ainda receber o reconhecimento dos stakeholders, deixando os interesses da empresa em segundo plano.

Jensen (2001), Silveira, Yoshinaga e Borba (2005) e Sundaram e Ikpen (2001) defendem que não é possível atender às necessidades de todas as partes interessadas, visto que haverá interesses conflitantes. Desse modo, quanto mais interessados existirem, mais conflitos de interesses existirão.

Friedman (1970) ainda afirma que as empresas devem se dedicar à maximização do resultado para o acionista e questões relacionadas à sociedade deverão ser de responsabilidade do Estado, das igrejas e dos sindicatos, uma vez que faz parte da função objetivo deles.

Entretanto essa ideia não é consenso, pois, de outro lado, existe a percepção da necessidade de devolução à sociedade, por parte das empresas, de ações que vão além do resultado econômico, a exemplo dos programas sociais (Ribeiro; Martins, 1993; Smith, Adhikari; Tondkar, 2005). Para Bastos e Lessa $(2008$, p. 3) "[...]a dicotomia entre a perspectiva do shareholder e do stakeholder pode ser discutida por meio da comparação entre o objetivo da lucratividade e o da responsabilidade."

Nessa linha, Carroll (1979) entende que a responsabilidade social deve ser vista sob os aspectos da maximização do resultado (responsabilidade econômica), do cumprimento das regras (responsabilidade legal), da ética (responsabilidade ética) e das ações na comunidade (responsabilidade discricionária). Essa ideia vai ao encontro ao que é preconizado pela teoria dos stakeholders, à medida que busca conciliar os interesses e as partes interessadas para que haja, então, uma convergência de ideias e de resultados, sejam eles econômicos ou sociais. 
Embora esse pensamento seja compartilhado por outros autores, tais como Ramanathan (1976) e McWilliams e Siegel (2001), ele sofre críticas sob alguns pontos de vista. A primeira diz respeito ao desvirtuamento da função objetivo para a qual as empresas foram constituídas.

Além disso, as críticas também permeiam a questão da operacionalidade dessa então convergência de interesses preconizada pela teoria dos stakeholders, haja vista que há dificuldades em identificar quais são essas partes interessadas, seu grau de importância para as organizações, qual o critério justo para conciliar tais interesses (Sternberg, 1999; Jensen, 2001). Sternberg (1999) afirma, inclusive, que a utilização da ideia preconizada pela teoria dos stakeholders é prejudicial a uma conduta organizacional responsável, o que é corroborado por Brigham, Gapenski e Ehrhard (2001) e por Hillman e Keim (2001).

A despeito dessa discussão, atualmente há uma crescente alocação de recursos em ações de responsabilidade social por parte das empresas (Milani Filho, 2008; Kpmg International, 2008). No entanto, há dúvidas acerca de seu real retorno seja para os acionistas, seja para os demais partícipes; bem como, quanto aos aspectos relacionados ao próprio planejamento da alocação dos recursos e ao alinhamento de objetivos organizacionais e da sociedade (Haydel, 1989; Peliano et al, 2002 e 2006; Bastos \& Lessa, 2008).

No caso das pesquisas realizadas por Peliano et al. (2002 e 2006), o que chama a atenção é a constatação de que a maioria das empresas pesquisadas acaba por alocar recursos em programas sociais sem qualquer planejamento, no que se refere à previsão de valores e/ou recursos.

Essas constatações contrariam o que seria tido como um comportamento socialmente responsável, uma vez que o gestor não exercerá uma função básica para a qual é constituído, a de maximizar os recursos organizacionais. Esse comportamento é o que Carr e Outhwaite (2009) comentam acerca da possibilidade de "corrupção nas práticas de responsabilidade social corporativa".

Apesar de as pesquisas nessa temática serem controversas no que diz respeito ao custobenefício da alocação de recursos em programas sociais ou, até mesmo, acerca da consideração dos stakeholders enquando foco estratégico, há autores que apesar das críticas, entendem que a referida temática (responsabilidade social corporativa) deve ser levada em consideração na estratégica das organizações, a exemplo de Jensen $(2003$, p. 1), que formula suas críticas a respeito da teoria dos stakeholders e que entende que "[...]uma empresa não pode maximizar seu valor se ignorar o interesse de seus stakeholders "ii".

No que tange à evidenciação, a origem da empresa pode ser determinante quanto ao tipo de informação a ser divulgada. Smith, Adhikari e Tondkar (2005) mencionam que o modelo de decisão, sobretudo aquele definido pela teoria dos stakeholders, influencia o tipo e a qualidade da informação prestada pela empresa aos seus usuários, chegando, inclusive, a afirmar que a sociedade acaba por influenciar e até definir a extensão do social disclosure nos relatórios anuais.

Tendo como base as considerações de Smith, Adhikari e Tondkar (2005), abre-se a expectativa de que as empresas sediadas em países que privilegiam os stakeholders possam ter uma maior atenção quanto às informações que possam satisfazer esses usuários, entre elas o social disclosure.

O teste empírico promovido por Roberts (1992) traz achados que vão ao encontro das considerações de Smith, Adhikari e Tondkar (2005), à medida que demonstram que há uma influência dos interesses dos stakeholders, quando alinhados à postura estratégica da organização, em promover um maior nível de social disclosure. Além desses fatores, o autor afirma que a teoria dos stakeholders é uma das bases de sustentação teórica que explica o comportamento estratégico das organizações quando se trata dessa variável.

Para Simnett, Vanstraelen e Chua (2009), a combinação de setor e empresas domiciliadas em países com orientação voltada para os stakeholders, faz com que haja uma maior busca pela asseguração dos relatórios de sustentabilidade, uma vez que essas informações fazem parte de um conjunto de informações relevantes para os investidores na tomada de decisão. 
No estudo realizado por Vanstraelen, Zarzerski e Robb (2003) acerca dos fatores que influenciam a divulgação de natureza não-financeira e voluntária em empresas sediadas em países europeus e anglo-saxões, foi constatado, entre outros fatores, que o país de origem é um fator que influencia no nível de divulgação daquele tipo de informação.

$\mathrm{Na}$ pesquisa realizada por Ball, Kothari e Robin (2000) a respeito das diferenças existentes em empresas classificadas entre shareholders ou stakeholders, quanto ao modelo de governança corporativa, constatou-se que as empresas do último grupo (stakeholders) possuem uma menor tempestividade no reconhecimento das variações econômicas no resultado contábil. Como consequência, os autores concluem que o maior disclosure promovido pelas empresas classificadas no modelo que privilegia os shareholders possui menor custo de agenciamento, em razão do monitoramento das ações dos gestores.

De forma análoga, as empresas classificadas no modelo que privilegia os stakeholders devem, em princípio, ter uma maior evidenciação das ações de responsabilidade social, possibilitando um maior monitoramento das decisões tomadas na alocação de recursos em programas sociais.

Em relação aos estudos realizados em empresas brasileiras, pode-se mencionar aqueles que analisaram fatores, tais como tamanho, setor, alavancagem, ações listadas em bolsas internacionais, auditoria e listagem em fundos socialmente responsáveis como aspectos que impulsionam a divulgação de informações sociais (Costa et. al., 2013; Gonçalves, De Medeiros \& Gonçalves, 2012; Cunha \& Ribeiro, 2008).

Além de tais aspectos, verifica-se também que a divulgação das informações sociais tende a aumentar quando há um formulário de referência, a exemplo do Balanço Social, GRI ou conteúdo recomendado pelas Nações Unidas (Ponto et. al., 2007; Oliveira et. al., 2009; Calixto, 2011)

Assim, o modo como a empresa entende a questão do que deverá evidenciar poderá, como afirmam Vanstraelen, Zarzerski e Robb (2003), Smith, Adhikari e Tondkar (2005), influenciar nas características das informações prestadas a seu público-alvo, isto é, informações mais relacionadas a aspectos legais e formais, ou às informações que vão além, que é a informação voluntária, incluindo aquelas relacionadas às ações de responsabilidade social.

\section{PROCEDIMENTOS DE PESQUISA}

A pesquisa é de natureza quali-quantitativa e do tipo documental, valendo-se da análise de conteúdo dos relatórios anuais e de sustentabilidade para extração das informações sociais (Richardson et al., 1999).

Para a delimitação do universo de pesquisa, foram utilizadas, como ponto de partida, as empresas classificadas no ranking das 500 Melhores e Maiores, divulgado pela Revista Exame, no ano de 2010. O ranking foi utilizado porque, além de permitir a escolha de empresas relevantes no mercado brasileiro, permite identificar o controle acionário da organização por país de origem.

Desse modo, considerando-se as características da pesquisa, houve a necessidade de se observar três aspectos: a) a identificação do controle da organização; b) a possibilidade de constituir uma base de empresas que permita classificá-las a partir de seu país de origem, diferenciando-as entre aquelas que privilegiam os stakehoders daquelas que privilegiam os shareholders, conforme classificação proposta por La Porta et al (1998), e c) a identificação quanto ao fato de a empresa ter tido no período analisado, ações de responsabilidade social externas.

Desde já, ressalta-se a limitação no uso dessa classificação, uma vez que ela tem seu fundamento a partir do sistema jurídico vigente no país (common law - shareholders; code law stakeholders), o que, por sua vez, poderá não retratar fielmente a característica do sistema contábil. Cabe destacar, porém, que, pela ausência de outro critério compatível para tal finalidade (segregação do modelo informacional entre stakeholders e shareholders), essa classificação tem sido utilizada em estudos dessa natureza, a exemplo dos estudos de Ball, Kothari e Robin (2000) e de Simnet, Vanstraelen e Chua (2009).

Revista de Gestão Social e Ambiental - RGSA, São Paulo, v. 7, n. 2, p. 53-70, maio/ago. 2013. 
Para analisar o nível de social disclosure das empresas da amostra, foi utilizado o índice de social disclosure proposto e validado por Gonçalves (2011), sustentado nos estudos de Ramanathan (1976), Haydel (1989) e Hammond e Miles (2004). Esse índice tem por objetivo avaliar a informação de natureza social sob a vertente das ações discricionárias empreendidas por empresas mediante programas sociais na comunidade, a partir das variáveis descritas na figura 1, a seguir.

\begin{tabular}{|c|c|c|c|}
\hline \multirow{14}{*}{ 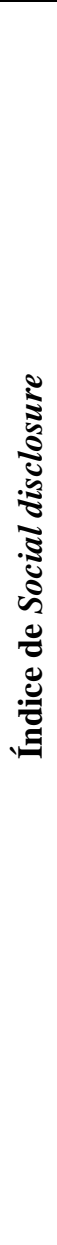 } & Dimensão & Direcionadores & Itens evidenciados \\
\hline & \multirow{8}{*}{$\begin{array}{l}\text { Informações } \\
\text { passadas }\end{array}$} & $\begin{array}{c}\text { Avaliação } \\
\text { (Ramanathan, 1976) }\end{array}$ & $\begin{array}{l}\text { VAR001 - Relação dos programas sociais com } \\
\text { os valores da empresa }\end{array}$ \\
\hline & & $\begin{array}{c}\text { Avaliação } \\
\text { (Ramanathan, 1976) }\end{array}$ & $\begin{array}{l}\text { VAR002 - Avaliação das necessidades locais } \\
\text { para a realização dos programas sociais }\end{array}$ \\
\hline & & $\begin{array}{c}\text { Mensuração } \\
\text { (Ramanathan, 1976) }\end{array}$ & $\begin{array}{l}\text { VAR005 - Descrição de objetivos e metas para } \\
\text { os programas sociais }\end{array}$ \\
\hline & & $\begin{array}{c}\text { Mensuração } \\
\text { (Ramanathan, 1976) }\end{array}$ & $\begin{array}{l}\text { VAR006 - Recursos financeiros alocados nos } \\
\text { programas sociais }\end{array}$ \\
\hline & & $\begin{array}{c}\text { Mensuração } \\
\text { (Ramanathan, 1976) }\end{array}$ & $\begin{array}{l}\text { VAR007 - Valor econômico e/ou financeiro dos } \\
\text { recursos humanos envolvidos em programas de } \\
\text { voluntariado }\end{array}$ \\
\hline & & $\begin{array}{c}\text { Mensuração } \\
\text { (Ramanathan, 1976) }\end{array}$ & $\begin{array}{l}\text { VAR008 - Valor econômico e/ou financeiro dos } \\
\text { recursos materiais destinados aos programas } \\
\text { sociais }\end{array}$ \\
\hline & & $\begin{array}{c}\text { Mensuração } \\
\text { (Ramanathan, 1976) }\end{array}$ & $\begin{array}{l}\text { VAR009 - Resultados sociais obtidos nos } \\
\text { programas sociais }\end{array}$ \\
\hline & & $\begin{array}{l}\text { Padrão de relatórios } \\
\text { (Ramanathan, 1976) }\end{array}$ & VAR011 - Distribuição do valor adicionado \\
\hline & \multirow{3}{*}{$\begin{array}{l}\text { Prospecções de } \\
\text { ações futuras }\end{array}$} & $\begin{array}{c}\text { Avaliação } \\
\text { (Ramanathan, 1976) }\end{array}$ & $\begin{array}{l}\text { VAR003 - Descrição de aspectos para a } \\
\text { melhoria dos resultados sociais obtidos nos } \\
\text { programas sociais }\end{array}$ \\
\hline & & $\begin{array}{c}\text { Avaliação } \\
\text { (Ramanathan, 1976) }\end{array}$ & $\begin{array}{l}\text { VAR004 - Descrição dos programas sociais } \\
\text { futuros e em andamento }\end{array}$ \\
\hline & & $\begin{array}{c}\text { Mensuração } \\
\text { (Ramanathan, 1976) }\end{array}$ & $\begin{array}{l}\text { VAR010 - Projeção do fluxo de caixa futuro da } \\
\text { alocação de recursos em programas sociais }\end{array}$ \\
\hline & \multirow{2}{*}{ Acessibilidade } & $\begin{array}{l}\text { Padrão de relatórios } \\
\text { (Ramanathan, 1976) }\end{array}$ & $\begin{array}{l}\text { VAR012 - Disponibilidade dos relatórios de } \\
\text { responsabilidade social }\end{array}$ \\
\hline & & $\begin{array}{l}\text { Padrão de relatórios } \\
\text { (Ramanathan, 1976) }\end{array}$ & $\begin{array}{l}\text { VAR013 - Frequência da divulgação dos } \\
\text { relatórios de responsabilidade social }\end{array}$ \\
\hline
\end{tabular}

Figura 1 - Indicadores do índice de social disclosure

Fonte: Gonçalves (2011)

Os relatórios de responsabilidade social das empresas amostradas constituíram a base para avaliação do social disclosure, realizada mediante a análise de conteúdo (Bardin, 1977), classificando-se a informação desde o nível "restrito" (nível inferior da informação), "baixo", "médio" até "amplo" (nível superior da informação). Esses níveis podem ser assim caracterizados (Gonçalves, 2011):

a) Restrito: o social disclosure é classificado nessa categoria se a empresa não divulga a informação avaliada pelo item ora proposto;

b) Baixo: o social disclosure é classificado nessa categoria se a empresa divulga a informação avaliada pelo item proposto, mas não o faz por programa social ou área de atuação, isto é, a informação é divulgada, de um modo geral, com uso de expressões, tais como "os programas sociais" e "as ações sociais";

c) Médio: o social disclosure é classificado nessa categoria se a empresa divulga a informação avaliada pelo item proposto, fazendo-a por área de atuação ou por alguns programas sociais;

d) Amplo: o social disclosure é classificado nessa categoria se a empresa divulga a informação avaliada pelo item proposto de maneira analítica, ou seja, se há informação referente a cada programa social; a característica dessa informação é de maior precisão e amplitude, como, por exemplo, "o projeto $x$...". 
As informações foram extraídas dos relatórios anuais e de sustentabilidade dos anos de 2009, 2010 e 2011. Optou-se por realizar a análise de três períodos para que se permitisse identificar a evolução quanto ao nível de evidenciação. A partir do universo inicial composto de 500 empresas, foi identificado que 190 possuíam controle externo. Dessas, foi possível analisar 40 empresas em 2009; 34, em 2010; e 32, em 2011, por possuírem e/ou apoiarem programas sociais externos, e ainda informações disponíveis em seus relatórios sociais. A distribuição das empresas pelo país de origem, bem como sua classificação é apresentada na figura 2, a seguir.

\begin{tabular}{|c|c|c|c|c|c|c|c|}
\hline \multicolumn{4}{|c|}{ Empresas Shareholders } & \multicolumn{4}{|c|}{ Empresas Stakeholders } \\
\hline \multirow{2}{*}{ Controle acionário } & \multicolumn{3}{|c|}{ Quantidade } & \multirow{2}{*}{ País controlador } & \multicolumn{3}{|c|}{ Quantidade } \\
\hline & 2009 & 2010 & 2011 & & 2009 & 2010 & 2011 \\
\hline Americano & 13 & 9 & 12 & Alemão & 2 & 3 & 2 \\
\hline Anglo-Indiano & 1 & 1 & - & Argentino & 1 & 2 & - \\
\hline \multirow[t]{11}{*}{ Inglês } & 2 & 3 & 1 & Belga & 1 & 1 & 1 \\
\hline & & & & Colombiano & 1 & 1 & 1 \\
\hline & & & & Espanhol & 2 & 2 & 2 \\
\hline & & & & Francês & 5 & 1 & 1 \\
\hline & & & & Franco-Belga & 1 & 1 & 1 \\
\hline & & & & Holandês & 1 & 2 & 2 \\
\hline & & & & Italiano & 3 & 2 & 3 \\
\hline & & & & Japonês & 2 & 2 & 3 \\
\hline & & & & Mexicano & 2 & 2 & 1 \\
\hline & & & & Português & 2 & 1 & - \\
\hline & & & & Suíço & 1 & 1 & 2 \\
\hline Total & 16 & 13 & 13 & Total & 24 & 21 & 19 \\
\hline
\end{tabular}

Figura 2 - Quantidade de empresas e relatórios por ano

Fonte: Dados da pesquisa (2013)

Com base na figura anterior, verifica-se que, por um lado, há uma quantidade maior de empresas classificadas de origem stakeholder nos três anos de análise (2009, 2010 e 2011) e uma maior diversificação em relação à origem dos países. Por outro, pode-se constatar que há uma maior quantidade de empresas de origem norte-americana, sendo 13 empresas em 2009, 9 em 2010 e 12 em 2011.

Considerando-se que a informação avaliada pode ser classificada entre os níveis restrito (1) a amplo (4) e que o índice possui 13 variáveis, cada empresa poderá obter, no mínimo, 13 pontos (todos os itens restritos) até 52 pontos (todos os itens amplos).

Tendo como base essa escala, analisada de forma individual para cada variável e empresa, a avaliação qualitativa do nível de social disclosure, conforme Gonçalves (2011), pode ser assim descrita:

\begin{tabular}{|c|c|}
\hline Pontuação & Nível de disclosure \\
\hline até 1,85 ponto & Ruim \\
\hline de 1,86 a 2,31 pontos & Baixo \\
\hline de 2,32 a 2,77 pontos & Médio \\
\hline acima de 2,78 pontos & Alto \\
\hline
\end{tabular}

Figura 3 - Classificação do nível de social disclosure

Fonte: Gonçalves (2011)

Com base na classificação feita inicialmente por empresa, foi realizada em seguida uma análise consolidada por grupo (stakeholder e shareholder) em cada ano e, posteriormente, uma análise comparativa dos resultados.

De forma complementar, foi realizado o teste, por meio da análise da variância, entre os resultados obtidos (nível de social disclosure e país de origem por grupo), para identificar se as diferenças encontradas pela análise qualitativa são estatisticamente significantes. 


\section{ANÁLISE DOS RESULTADOS}

A análise do social disclosure quanto aos programas sociais externos é realizada sob a perspectiva de três dimensões: informações passadas, prospecções de ações futuras e acessibilidade das informações. Nesse sentido, as variáveis listadas de (1) a (8) possuem, predominantemente, a descrição de ações passadas; as variáveis listadas de (9) a (11) possuem como característica a avaliação de ações que devem ser realizadas em momento futuro e, por fim, as variáveis (12) e (13) avaliam o modo como as informações são disponibilizadas.

Na figura, a seguir, está disposto o resultado obtido em cada um dos grupos (stakeholders e shareholders) para cada uma das variáveis avaliadas, nos anos de 2009, 2010 e 2011.

\begin{tabular}{|c|c|c|c|c|c|c|}
\hline \multirow{2}{*}{ Variáveis } & \multicolumn{3}{|c|}{ Shareholders } & \multicolumn{3}{|c|}{ Stakeholders } \\
\hline & 2009 & 2010 & 2011 & 2009 & 2010 & 2011 \\
\hline $\begin{array}{l}\text { (1) Relação dos programas sociais com os } \\
\text { valores da empresa }\end{array}$ & $\begin{array}{l}\text { Médio } \\
(2,50)\end{array}$ & $\begin{array}{l}\text { Médio } \\
(2,38)\end{array}$ & $\begin{array}{l}\text { Baixo } \\
(1,92)\end{array}$ & $\begin{array}{l}\text { Médio } \\
(2,33)\end{array}$ & $\begin{array}{l}\text { Alto } \\
(2,81)\end{array}$ & $\begin{array}{l}\text { Baixo } \\
(2,05)\end{array}$ \\
\hline $\begin{array}{l}\text { (2) Avaliação das necessidades locais para } \\
\text { realização dos programas sociais }\end{array}$ & $\begin{array}{l}\text { Ruim } \\
(1,50)\end{array}$ & $\begin{array}{l}\text { Ruim } \\
(1,46)\end{array}$ & $\begin{array}{l}\text { Ruim } \\
(1,23)\end{array}$ & $\begin{array}{l}\text { Ruim } \\
(1,50)\end{array}$ & $\begin{array}{l}\text { Ruim } \\
(1,44)\end{array}$ & $\begin{array}{l}\text { Ruim } \\
(1,53)\end{array}$ \\
\hline $\begin{array}{l}\text { (3) Descrição de objetivos e metas para os } \\
\text { programas sociais }\end{array}$ & $\begin{array}{c}\text { Alto } \\
(3,00)\end{array}$ & $\begin{array}{c}\text { Alto } \\
(3,00)\end{array}$ & $\begin{array}{l}\text { Baixo } \\
(1,92) \\
\end{array}$ & $\begin{array}{c}\text { Alto } \\
(3,00) \\
\end{array}$ & $\begin{array}{l}\text { Alto } \\
(2,90)\end{array}$ & $\begin{array}{l}\text { Médio } \\
(2,32)\end{array}$ \\
\hline $\begin{array}{l}\text { (4) Recursos financeiros alocados nos } \\
\text { programas sociais }\end{array}$ & $\begin{array}{l}\text { Médio } \\
(2,63)\end{array}$ & $\begin{array}{l}\text { Baixo } \\
(2,31)\end{array}$ & $\begin{array}{l}\text { Baixo } \\
(2,23)\end{array}$ & $\begin{array}{l}\text { Baixo } \\
(2,25)\end{array}$ & $\begin{array}{l}\text { Baixo } \\
(2,00)\end{array}$ & $\begin{array}{l}\text { Baixo } \\
(2,16)\end{array}$ \\
\hline $\begin{array}{l}\text { (5) Valor econômico e/ou financeiro dos } \\
\text { recursos humanos envolvidos em programas de } \\
\text { voluntariado }\end{array}$ & $\begin{array}{l}\text { Baixo } \\
(1,88)\end{array}$ & $\begin{array}{l}\text { Ruim } \\
(1,69)\end{array}$ & $\begin{array}{l}\text { Baixo } \\
(2,00)\end{array}$ & $\begin{array}{l}\text { Baixo } \\
(1,96)\end{array}$ & $\begin{array}{l}\text { Ruim } \\
(1,67)\end{array}$ & $\begin{array}{l}\text { Ruim } \\
(1,89)\end{array}$ \\
\hline $\begin{array}{l}\text { (6) Valor econômico e/ou financeiro dos } \\
\text { recursos materiais destinados aos programas } \\
\text { sociais }\end{array}$ & $\begin{array}{l}\text { Ruim } \\
(1,50)\end{array}$ & $\begin{array}{l}\text { Ruim } \\
(1,46)\end{array}$ & $\begin{array}{l}\text { Ruim } \\
(1,38)\end{array}$ & $\begin{array}{l}\text { Ruim } \\
(1,54)\end{array}$ & $\begin{array}{l}\text { Ruim } \\
(1,62)\end{array}$ & $\begin{array}{l}\text { Ruim } \\
(1,42)\end{array}$ \\
\hline $\begin{array}{l}\text { (7) Resultados sociais obtidos nos programas } \\
\text { sociais }\end{array}$ & $\begin{array}{l}\text { Médio } \\
(2,75)\end{array}$ & $\begin{array}{l}\text { Médio } \\
(2,38)\end{array}$ & $\begin{array}{l}\text { Baixo } \\
(2,15)\end{array}$ & $\begin{array}{l}\text { Médio } \\
(2,67)\end{array}$ & $\begin{array}{l}\text { Médio } \\
(2,67)\end{array}$ & $\begin{array}{r}\text { Médio } \\
(2,68)\end{array}$ \\
\hline (8) Distribuição do valor adicionado & $\begin{array}{c}\text { Alto } \\
(2,88) \\
\end{array}$ & $\begin{array}{l}\text { Médio } \\
(2,77)\end{array}$ & $\begin{array}{l}\text { Baixo } \\
(2,08)\end{array}$ & $\begin{array}{l}\text { Médio } \\
(2,71)\end{array}$ & $\begin{array}{l}\text { Alto } \\
(2,81)\end{array}$ & $\begin{array}{l}\text { Médio } \\
(2,47)\end{array}$ \\
\hline $\begin{array}{l}\text { (9) Descrição de aspectos para melhoria dos } \\
\text { resultados sociais obtidos nos programas sociais }\end{array}$ & $\begin{array}{l}\text { Ruim } \\
(1,19)\end{array}$ & $\begin{array}{l}\text { Ruim } \\
(1,00)\end{array}$ & $\begin{array}{l}\text { Ruim } \\
(1,15)\end{array}$ & $\begin{array}{l}\text { Ruim } \\
(1,04)\end{array}$ & $\begin{array}{l}\text { Ruim } \\
(1,00)\end{array}$ & $\begin{array}{l}\text { Ruim } \\
(1,21)\end{array}$ \\
\hline $\begin{array}{l}\text { (10) Descrição dos programas sociais futuros e } \\
\text { em andamento }\end{array}$ & $\begin{array}{l}\text { Baixo } \\
(1,88)\end{array}$ & $\begin{array}{l}\text { Ruim } \\
(1,69)\end{array}$ & $\begin{array}{c}\text { Ruim } \\
(1,69)\end{array}$ & $\begin{array}{l}\text { Ruim } \\
(1,54)\end{array}$ & $\begin{array}{c}\text { Ruim } \\
(1,67)\end{array}$ & $\begin{array}{l}\text { Ruim } \\
(1,68)\end{array}$ \\
\hline $\begin{array}{l}\text { (11) Projeção do fluxo de caixa futuro da } \\
\text { alocação de recursos em programas sociais }\end{array}$ & $\begin{array}{l}\text { Ruim } \\
(1,25)\end{array}$ & $\begin{array}{l}\text { Ruim } \\
(1,08)\end{array}$ & $\begin{array}{l}\text { Ruim } \\
(1,15) \\
\end{array}$ & $\begin{array}{l}\text { Ruim } \\
(1,04)\end{array}$ & $\begin{array}{l}\text { Ruim } \\
(1,05)\end{array}$ & $\begin{array}{l}\text { Ruim } \\
(1,00)\end{array}$ \\
\hline $\begin{array}{lrlrl}(12) & \text { Disponibilidade } & \text { dos } & \text { relatórios } & \text { de } \\
\text { responsabilidade social } & & & \\
\end{array}$ & $\begin{array}{c}\text { Alto } \\
(4,00)\end{array}$ & $\begin{array}{c}\text { Alto } \\
(4,00)\end{array}$ & $\begin{array}{c}\text { Alto } \\
(4,00)\end{array}$ & $\begin{array}{c}\text { Alto } \\
(4,00)\end{array}$ & $\begin{array}{c}\text { Alto } \\
(4,00)\end{array}$ & $\begin{array}{c}\text { Alto } \\
(4,00)\end{array}$ \\
\hline $\begin{array}{l}\text { (13) Frequência da divulgação dos relatórios de } \\
\text { responsabilidade social }\end{array}$ & $\begin{array}{c}\text { Alto } \\
(3,38)\end{array}$ & $\begin{array}{c}\text { Alto } \\
(3,54)\end{array}$ & $\begin{array}{c}\text { Alto } \\
(3,54)\end{array}$ & $\begin{array}{c}\text { Alto } \\
(3,50)\end{array}$ & $\begin{array}{c}\text { Alto } \\
(3,62)\end{array}$ & $\begin{array}{c}\text { Alto } \\
(3,26)\end{array}$ \\
\hline Resultado final & $\begin{array}{c}\text { Baixo } \\
(\mathbf{3 0 , 3 1 )}\end{array}$ & $\begin{array}{l}\text { Baixo } \\
(28,77)\end{array}$ & $\begin{array}{c}\text { Baixo } \\
(\mathbf{2 6 , 4 6 )}\end{array}$ & $\begin{array}{l}\text { Baixo } \\
(29,08)\end{array}$ & $\begin{array}{l}\text { Baixo } \\
(29,19)\end{array}$ & $\begin{array}{c}\text { Baixo } \\
(27,68)\end{array}$ \\
\hline
\end{tabular}

Figura 4 - Resultados qualitativos listados por variável e grupo para os anos de 2009, 2010 e 2011

Fonte: Dados da pesquisa (2013)

Os resultados dispostos na figura 4 são apresentados por meio da classificação qualitativa obtida para cada um dos grupos e do valor médio alcançado em cada uma das variáveis.

Pode-se identificar, desde já, que os resultados qualitativos não apontam uma diferença entre os grupos analisados, uma vez que, para os anos de 2009, 2010 e 2011, os dois grupos apresentaram o mesmo resultado final - baixo. Sob o ponto de vista de tendência da melhoria da informação, pode-se constatar que as empresas classificadas no grupo shareholders tiveram uma maior queda no que tange ao nível de evidenciação, uma vez que, no ano de 2009, obtiveram 30,31 pontos; em 2010, 28,77 pontos; e, em 2011, um total de 26,46 pontos.

Entretanto, a referida tendência não pode ser generalizada quando se trata da prática da evidenciação social em empresas brasileiras. Por exemplo, na pesquisa de Ponte et. al. (2007), foi 
identificada, para as empresas analisadas, uma melhoria na divulgação de informações por meio do Balanço Social e de suas práticas de responsabilidade social no período compreendido entre os anos de 2002 a 2005, tendo sido a mesma tendência observada no estudo de Gonçalves, De Medeiros e Gonçalves (2012) para o período de 2005 a 2009.

Desse modo, para se avaliar as características informacionais dessa diminuição em termos qualitativos, foram analisadas individualmente as variáveis avaliadas.

A primeira variável - relação dos programas sociais com os valores da empresa - tem por objetivo identificar os motivos pelos quais a empresa decidiu apoiar um determinado programa social e como este contribui para divulgar os valores da empresa. Para Porter e Kramer (2002) e para Saiia, Carrol e Buchholtz (2003), a decisão em alocar recursos em programas sociais deve estar atrelada à estratégia da organização e, por isso, estes devem refletir valores da organização promotora das ações.

Para o primeiro grupo (shareholders), o resultado encontrado é médio para os anos de 2009 e 2010, revelando que a relação entre programas sociais e valores organizacionais é realizada por área de atuação e não por ação empreendida. Como consequência desse resultado, não é possível fazer inferências acerca de onde cada programa social se encaixa no aspecto estratégico da organização e, ainda se pode identificar os possíveis motivos do gestor de alocar mais recursos econômico-financeiros em um programa em detrimento de outro.

Analisando o ano de 2011, verifica-se, para o referido grupo, uma diminuição na qualidade da informação, dado que o resultado obtido foi baixo, a mesma tendência ficou evidente no resultado geral para as empresas do grupo shareholders.

Já para o segundo grupo (stakeholders), há uma tendência de melhoria quando analisado os resultados no ano de 2009 médio e em 2010 alto. Contudo essa tendência se inverte em 2011, cujo resultado apresentado é baixo, porém ainda com uma tendência geral (2009-2011) considerada média.

Essa tendência (2009-2011) revela que as empresas classificadas neste grupo buscaram realizar a divulgação por área de atuação, a mesma tendência foi encontrada nos anos de 2009 e 2010 para o grupo shareholders. Somente quando analisada a tendência para igual período, o grupo stakehoders possui um maior detalhamento de suas informações sociais no que tange a justificar a escolha das ações de responsabilidade social, dado que o faz por programa social apoiado. Com isso, permite uma análise mais acurada acerca das decisões tomadas pelo gestor durante aquele período, e ainda, acerca de possíveis decisões futuras, dado que há uma maior clareza do que se espera de cada um dos programas sociais apoiados.

Sob essa perspectiva, Haydel (1989) afirma que as empresas, ao relacionar seus programas sociais com os objetivos estratégicos da organização, passam a demonstrar a importância que essas ações possuem para a corporação.

A segunda variável - avaliação das necessidades locais para a realização de programas sociais - busca identificar se os programas sociais são, de fato, uma demanda da sociedade local, o que permite, por sua vez, avaliar a convergência entre ações na comunidade e os valores organizacionais. O resultado para os dois grupos e períodos é ruim, mostrando que as ações sociais são realizadas não necessariamente em razão de uma demanda da comunidade. Além disso, foi identificado que somente uma empresa teve o resultado considerado alto, e essa pertence ao grupo classificado como shareholders.

No estudo realizado por Gonçalves, De Medeiros e Gonçalves (2012), observa-se, também, de modo geral, a mesma tendência, com exceção para as empresas listadas em fundos socialmente responsáveis, cujo resultado obtido foi médio. Esse resultado justifica-se em razão das exigências das empresas, ao buscarem a listagem nos referidos fundos, necessitam readequar suas práticas internas de responsabilidade social, incluindo as de evidenciação.

A terceira variável - descrição dos objetivos e metas para os programas sociais - permitiu observar uma tendência final cujo resultado é médio para ambos os grupos, não importando a origem do controle acionário. Apesar desse resultado final, o destaque negativo se deve ao fato de 
que, em ambos, há uma tendência de menor evidenciação. A divulgação total da referida variável possibilitaria ao usuário externo identificar os motivos que levaram as empresas a praticarem tais ações, além de possibilitar a associação das metas e objetivos propostos com os resultados obtidos em cada programa social.

Esse resultado não corrobora os achados de Costa et. al. (2013), que identificaram nas empresas analisadas uma predominância da divulgação da informação social atrelada à ações externas e de natureza não-monetária.

A quarta variável - recursos financeiros alocados nos programas sociais - tem por objetivo identificar a quantia que foi alocada em cada um dos programas sociais externos. O resultado encontrado para as empresas classificadas no grupo stakeholders foi baixo para esta variável, o que significa que as empresas divulgam somente o valor total alocado, sem especificar a área e o programa social, enquanto as empresas listadas no grupo dos shareholders apresentaram um resultado final médio (2,39 pontos), considerando o período de 2009 a 2011. Contudo, observa-se que a pontuação obtida de 2,39 está muito próxima da fronteira entre baixo $(1,86$ a 2,31) e médio (2,32 a 2,77), além de haver uma tendência de queda da referida informação, dado que, em 2010 e em 2011, os resultados foram classificados no nível baixo.

O que chama a atenção nessa variável é que a divulgação dos recursos financeiros alocados em programas sociais se dá, predominantemente, por intermédio do Balanço Social, todavia ainda de forma incompleta, dado que se informa o valor total dos recursos alocados, sem, contudo, atrelar a quantia à área de atuação e aos programas.

Apesar desse aspecto, essa informação, no caso das empresas analisadas, ainda é obtida em razão da orientação dada a partir de relatórios que apresentam algum padrão para a divulgação da referida informação, conforme apontam os achados de Oliveira et. al. (2009) e de Calixto (2011).

Nas variáveis - valor econômico elou financeiro dos recursos humanos envolvidos em programas sociais e valor econômico elou financeiro dos recursos materiais destinados aos programas sociais - os grupos tiveram a mesma tendência no período analisado, com um resultado considerado ruim. Esse resultado aponta para o fato de que as empresas não deixam, de forma explícita, possíveis alocações de recursos na forma de horas de voluntariado por meio de seus colaboradores, ou ainda, na forma de doação de recursos materiais. Apesar dessa tendência, cabe destacar a divulgação realizada pela empresa Roche (controle - suíço), em seu relatório de sustentabilidade de 2009, em que informa o total de horas dedicadas ao Programa de Voluntariado nos anos de 2007, 2008 e 2009. Observa-se a intenção da empresa de possibilitar ao usuário externo fazer não somente a comparação entre os anos, mas, sobretudo, de ter uma ideia acerca do gasto total (financeiro e econômico) para a realização das ações de responsabilidade social.

A sétima variável - resultados obtidos nos programas sociais - tem por objetivo identificar a materialização dos impactos provocados pelos programas sociais apoiados ou realizados na comunidade. $\mathrm{O}$ resultado obtido para os dois segmentos nos três anos é médio, uma vez que as informações divulgadas dos resultados obtidos são realizadas por área de atuação. O resultado, de modo geral, é o esperado, em razão da necessidade da apresentação de indicadores que reflitam em melhorias na imagem organizacional.

Apesar da evidenciação desses resultados repercutirem, em princípio, em uma melhoria na imagem organizacional, segundo Machado Filho e Zylbersztajn (2003), as empresas precisam de avaliações sistemáticas de forma a apontar ações e resultados que tragam benefícios à comunidade. Nesse aspecto, destaca-se que, embora esses resultados sejam apresentados, não é possível avaliar se tais programas estão alinhados aos desejos da comunidade atingida por eles, conforme foi identificado na variável (2) para os dois grupos.

A oitava variável - distribuição do valor adicionado - diz respeito à evidenciação da riqueza gerada pela empresa, cuja informação é passível de verificação por terceiros. O resultado apresentado pelas empresas classificadas no primeiro grupo (shareholders) para o ano de 2009 é alto; para 2010 é médio; e para 2011, é baixo. Quanto ao segundo grupo (stakeholders), para o ano de 2009 é médio; para 2010 é alto; e para 2011 é médio. Embora essa informação atualmente seja 
de caráter obrigatório tanto para as empresas de grande porte quanto para as empresas de capital aberto, o fator preponderante para esse resultado é o de que há empresas na amostra que não se enquadraram nos itens de obrigatoriedade, e, nesse sentido, passaram a divulgar a informação sem submetê-la a uma verificação por terceiros (resultado - médio).

As variáveis de (9) a (11) possuem como característica aspectos de ações futuras, e os resultados encontrados para ambos os grupos no período analisado é de uma tendência ruim, exceto para o grupo das empresas classificadas como shareholders no ano de 2009 para a variável descrição dos programas sociais futuros e em andamento, cujo resultado foi baixo $(1,88)$, porém muito próximo de ser considerado ruim, cuja faixa de pontuação vai de 1,00 a 1,85.

Desse modo, o que se observa é que as variáveis que avaliam ações futuras relacionadas aos programas sociais não são divulgadas, o que pode representar incertezas acerca da continuidade ou não das ações a serem realizadas ou até falta de comprometimento destes para com a continuidade dos programas sociais, corroborando os achados de Gonçalves, De Medeiros e Gonçalves (2012) e de Vaz et. al. (2010).

Por fim, as variáveis (12) e (13), que avaliam aspectos relacionados à acessibilidade e à periodicidade dos relatórios, nos três períodos e nos dois grupos, apresentaram uma tendência de resultado alto, o que demonstra que os relatórios estão disponíveis na internet e ainda há informação que possibilita identificar em que momento estes foram ou serão disponibilizados ao usuário.

De forma complementar a análise qualitativa, esta etapa tem por objetivo analisar, por meio das variâncias dos resultados, se as diferenças obtidas no nível de social disclosure entre os grupos (stakeholders e shareholders) são estatisticamente significantes ou não.

Assim sendo, antes de se proceder à análise propriamente dita, testou-se a normalidade da base de dados, haja vista que o referido teste parte das premissas de que a extração dos resultados advém de uma população cuja distribuição é normal e com a mesma variância $\sigma^{2}$. Para tanto, realizou-se o teste de Kolgomorov-Smirnov cujo resultado (0.225) não rejeitou a hipótese nula para a distribuição normal, $p$-valor superior ao nível de significância $(\alpha=0,05)$.

Uma vez que a amostra tem uma distribuição normal, procedeu-se à análise da variância (Anova) cujo resultado pode ser observado na tabela a seguir.

Tabela 1 - Anova (oneway): nível de social disclosure e país de origem (stakeholders e shareholders)

\begin{tabular}{lccccc}
\hline & Sum of Squares & Df & Mean Square & F & p-value \\
\hline Between Groups & .347 & 1 & .347 & .025 & .874 \\
Within Groups & 1417.311 & 103 & 13.760 & & \\
$\quad$ Total & 1417.657 & 104 & & & \\
\hline
\end{tabular}

Fonte: Dados da pesquisa (2013)

Ao nível de significância $(\alpha=0,05)$, a hipótese nula não é rejeitada $(0,874)$, o que mostra que não há diferenças estatisticamente significantes entre as variáveis, ratificando que, a variável país de origem não é determinante no nível de social disclosure das subsidiárias estrangeiras no Brasil. Para dar confiabilidade ao referido resultado, é apresentado a seguir o teste de homogeneidade das variâncias - teste de Levene.

Tabela 2 - Teste Levene: nível de social disclosure e país de origem (stakeholders e shareholders)

\begin{tabular}{c|c|c|c|c}
\hline Levene Statistic & df1 & df2 & p-value. & \\
\hline .604 & 1 & 103 & .439 & \\
\hline
\end{tabular}

Fonte: Dados da pesquisa (2013)

De acordo com o teste de Levene, conclui-se que as variâncias são homogêneas, ao nível de significância $(\alpha=0,05)$, uma vez que o $p$-valor foi maior $(0,439)$, validando o resultado apresentado na Tabela 1. 


\section{DISCUSSÃO DOS RESULTADOS}

Estudos como o de Ball, Kothari e Robin (2000) de Vanstraelen, Zarzerski e Robb (2003) e de Smith, Adhikari e Tondkar (2005) apontam que a origem do país é uma variável determinante, seja no que é divulgado (aspectos qualitativos da informação) bem como o nível dessa divulgação (aspectos quantitativos).

Partindo da hipótese de que a origem acionária poderia influenciar o nível de evidenciação social em subsidiárias de empresas estrangeiras no Brasil, os resultados, quer qualitativos, quer quantitativos, apontam que não há diferenças entre os grupos de empresas analisados e classificados entre shareholders e stakeholders.

Em relação à dimensão informações passadas, em ambos os grupos observou-se uma tendência na divulgação de quatro variáveis classificadas como média, uma classificada como baixa e três classificadas como ruim. Na dimensão prospecções de ações futuras, as empresas classificadas como shareholders apresentaram melhores resultados em todos os itens analisados quando analisada a pontuação obtida. Contudo, quanto ao resultado qualitativo, nos dois grupos a tendência é uma divulgação classificada como ruim.

Nessa dimensão, no item descrição dos programas futuros e em andamento, em 2009, o resultado apresentado pelas empresas shareholders (baixo) foi superior em relação ao grupo das empresas stakeholders (ruim). Mesmo assim, pode-se notar que o nível de evidenciação social ainda é baixo em relação a esse item.

$\mathrm{Na}$ dimensão acessibilidade (dois itens), houve equilíbrio nos resultados encontrados nos dois grupos no item disponibilidade dos relatórios de responsabilidade social. Em relação ao item frequência da divulgação dos relatórios de responsabilidade social, as empresas classificadas no grupo shareholders apresentaram pontuação ligeiramente melhor.

Os resultados, portanto, não corroboram os achados de Roberts (1992), que verificou que influência dos stakeholders alinhada à postura estratégica da organização é fator que interfere no nível de social disclosure. Pode-se inferir esse aspecto não somente pela baixa qualidade da informação divulgada, mas também pelo tipo de informação, uma vez que as empresas divulgam preponderantemente aspectos relacionados aos benefícios gerados pelos programas sociais, contudo, sem mencionar como se deu o seu planejamento, como estes estão alinhados aos objetivos e valores da organização e se estes serão objeto de continuidade, dado que as variáveis relacionadas com as prospecções de ações futuras possuem uma tendência de evidenciação considerada ruim em ambos os grupos.

Diante de tais resultados, conclui-se que a origem do país controlador não é fator de influência para o nível de social disclosure, uma vez que os resultados encontrados nos dois grupos foram parecidos, sendo, em alguns casos, melhores em empresas classificadas no grupo shareholders $\left(\mathrm{H}_{0}\right.$ - não rejeitada). Contudo, apesar de estudos como o de Ponte et. al. (2007) e Gonçalves, De Medeiros e Gonçalves (2012) apontarem que há uma tendência de melhoria quanto ao nível de evidenciação social em empresas brasileiras, a partir dos resultados ora obtidos, não é possível inferir que a não existência de diferenças entre os grupos se dê em razão de uma melhoria conjunta nas práticas de evidenciação, dado o baixo nível de divulgação registrado.

Tendo como base os estudos anteriores que buscaram analisar os fatores que determinam a evidenciação social, pode-se, portanto, creditar que aspectos como tamanho, auditoria, alavancagem, setor, adesão a fundos socialmente responsáveis e listagem em bolsas internacionais, são os responsáveis pelo maior nível de evidenciação em empresas brasileiras (Cunha \& Ribeiro, 2008; Gonçalves, De Medeiros \& Gonçalves, 2012).

Além de tais aspectos, a regulamentação setorial deve ser outro fator de alavancagem da informação social, como foi identificado nos estudos de Calixto (2008) e Calixto (2011), como é o caso do setor elétrico.

Ainda, considerando o nível de evidenciação obtido para as empresas da amostra, também não é possível inferir que essas informações são consideradas relevantes como parte de uma política 
de divulgação, dado que, de uma pontuação que varia de 13 a 52 pontos, o grupo que teve a melhor média entre os anos analisados foram as empresas classificadas como shareholders e, ainda, com somente 30,31 pontos no ano de 2009 e com uma diminuição para os anos de 2010 - 28,77 pontos e 2011 - 26,46, obtendo-se um resultado considerado baixo, o que se justifica por se tratar de informações que não estejam diretamente relacionadas a um padrão de divulgação, a exemplo dos achados de Ponte et. al.(2007) e Oliveira et. al. (2009).

\section{CONSIDERAÇÕES FINAIS}

Com o objetivo de analisar se a origem do controle acionário é fator determinante no nível de social disclosure, esta pesquisa alcançou uma amostra de 40 empresas no ano de 2009; 34 em 2010; e 32 em 2011 por satisfazerem os critérios de análise.

Segregadas por grupo (shareholders e stakeholders), considerando-se o país de origem do controlador e a classificação proposta por La Porta et al. (1998), os resultados encontrados, tanto qualitativos quanto quantitativos, indicam que a origem do país não é determinante na quantidade ou na qualidade do social disclosure e, ainda, que a divulgação realizada por essas empresas necessitam de melhorias, dado que o nível de evidenciação para os grupos e anos analisados é considerado baixo (classificação final).

Além disso, observa-se que o aumento da divulgação de informações sociais está atrelado a aspectos que orientam os preparadores na elaboração de seus relatórios, a exemplo do Balanço Social ou de guias como o da Organização das Nações Unidas, como observado em estudos anteriores (Calixto, 2011; Oliveira et. al., 2009).

Acredita-se que aspectos, tais como a cultura local - dado que o nível de social disclosure não foi influenciado pela origem do país controlador - a orientação contábil voltada à regulação haja vista que as informações divulgadas estão voltadas a manuais ou a procedimentos orientativos - sejam aspectos que determinam o aumento da evidenciação social para as empresas ora analisadas (MacArthur, 1996).

Com base nos achados deste estudo, verifica-se que há grupos diferenciados de empresas que devem ter um tratamento também diferenciado. Um grupo é aquele formado por grandes empresas, que possui como principais determinantes para a alavancagem de sua evidenciação social aspectos como adesão em fundos socialmente responsáveis, ações listadas em bolsas internacionais, auditoria e tamanho (Cunha \& Ribeiro, 2008; Gonçalves, De Medeiros \& Gonçalves, 2012). De outra sorte, tem-se outro grupo de empresas, que, por não terem tais estímulos ou características, passam a evidenciar preponderantemente informações que estão contidas em manuais ou procedimentos orientativos.

Assim, conclui-se que um maior incentivo por parte dos organismos reguladores poderia fazer com que houvesse uma melhor prática acerca da divulgação social em empresas brasileiras, considerando-se os aspectos e resultados ora apresentados.

Como sugestão para pesquisas futuras, recomenda-se a elaboração de uma classificação que possa identificar o modelo informacional para as empresas de diferentes origens no que tange à informação voluntária. Entre elas, o social disclosure, pode ser útil, na medida em que permite avaliar possíveis diferenças existentes em razão de aspectos culturais e sociais.

Por fim, como limitação da pesquisa, pode-se mencionar que, para analisar o nível de social disclosure das empresas, este estudo leva em consideração apenas um item, a origem do país controlador, bem como a subjetividade inerente ao processo de análise de conteúdo. Dessa forma, como sugestão adicional para pesquisas futuras, tem-se a possibilidade da análise do nível de social disclosure das subsidiárias estrangeiras no Brasil, considerando-se mais de um fator (tamanho, setor, listagem em fundos socialmente responsáveis, entre outros), além da origem do controle acionário. 


\section{REFERÊNCIAS}

Ball, R., Kothari, S. P., Robin, A. (2000) The effect of international institutional factors on properties of accounting earnings. Journal of Accounting and Economics, 29(1), 1-51.

Banco Central do Brasil - BCB - Investimento Estrangeiro Direto. Recuperado em: 13 out.2011, de: http://www.bcb.gov.br/.

Baron, D.P. (2001) Private politics, corporate social responsibility, and integrated strategy. Journal of Economics and Management Strategy, 10(1), Spring.

Bastos, B.E.N., Lessa, A.K.M. da. (2008) Responsabilidade social empresarial e o propósito organizacional sob um olhar cognitivista: o caso da Itamaracá Transportes. In. Encontro da Associação Nacional dos Programas de pós-graduação em Administração (ENANPAD), 32, 2008, Rio de Janeiro, Anais... Rio de Janeiro: ANPAD, 1 CD-ROM.

Braga, C. et al.(2011) A influência da origem do controle acionário no nível de disclosure ambiental no setor de energia elétrica no Brasil. In. Encontro da Associação Nacional dos Programas de pós graduação em Administração (ENANPAD), 35, 2011, Rio de Janeiro, Anais... Rio de Janeiro/RJ: ANPAD, 1 CD-ROM.

Branco, M. C., Rodrigues, L. L.(2008) Factors influenting social responsibility disclosure by portuguese companies. Journal of Business Ethics, 83, 685-701.

Brigham, E.E., Gapenski, L.C., Ehrhard, M.C. (2001) Administração financeira: teoria e prática. Tradução: Alexandre Loureiro Guimarães Alcântara, José Nicolas Albuja Salazar. São Paulo: Atlas.

Calixto, L. (2008) Responsabilidade socioambiental: pública ou privada? Revista Contabilidade Vista e Revista, 19(3), 123-147, jul./set.

Calixto, L.(2011) Responsabilidade socioambiental: a divulgação de relatórios na América Latina. Tese (Doutorado) Escola de Administração de Empresas de São Paulo da Fundação Getulio Vargas, São Paulo.

Camargos, M. A. de, Romero, J. A. R.(2006) Análise empírica da reação do mercado de capitais brasileiro a eventos corporativos: teste conjunto da hipótese de eficiência do mercado. Revista de Gestão USP, São Paulo, 13(3), 57-74, jul./set.

Campbell, D., Moore, G., Shrives, P.(2006) Cross-sectional effects in community disclosure. Accounting, Auditing \& Accountability, Journal, 19(1), 96-114.

Carr, I., Outhwaite, O. (2009) Investigating the impact of anti-corruption strategies on international business: an interim report. Recuperado em: 18 set.2009, de: <http://ssrn.com/abstract=1410642〉.

Carroll, A. B. (1979) A three-dimensional conceptual model of corporate performance. Academy of Management Review, Biarcliff Manor, 4(4), 497-505.

Chih, H., Chih, H., Chen, T.N.(2010) On the determinants of corporate social responsibility: international evidence on the financial industry. Journal of Business Ethics, 93, 115-135.

Choi, F. D. S., Meek, G. K.(2008) International accounting. (6. ed.) New Jersey: Pearson Prentice Hall. 
Clarkson, P. M., Li, Y., Richardson, G. D., Vasvari, F. P.(2008) Revisiting the relation between environmental performance and environmental disclosure: an empirial analysis. Accounting, Organizations and Society, 33, 303-327.

Cochran, P.L., Wood, R.A.(1984) Corporate social responsibility and financial performance. Academy of Management Journal, 27(1), 42-56.

Costa, M. I., Torres, L. S., Vasconcelos, A. C., De Luca, M. M. M. (2013) Classificação do conteúdo dos relatórios de sustentabilidade de empresas premiadas por suas práticas de responsabilidade socioambiental. REPeC - Revista de Educação e Pesquisa em Contabilidade, Brasília, 7(2), art. 3, 147-166, abr./jun. 2013.

Cunha, J. V. A., Ribeiro, M. S. (2008) Divulgação voluntária de informações de natureza social: um estudo nas empresas brasileiras. R.Adm. Eletrônica, São Paulo, 1(1), art.6, jan./jun.

Friedman, M.(1970) The social responsibility of business is increase its profits. The New York Times Magazine, 13, Sep.

Gamerschlag, R., Moeller, K., Verbeeten, F. Determinants of voluntary csr disclosure: empirical evidence from germany. Review of Managerial Science, 4.

Gonçalves, R. de S. (2011) Social disclosure e custo de capital próprio em empresas brasileiras de capital aberto. 165 f. Tese (Doutorado) - Faculdade de Economia, Administração e Ciências Contábeis e Atuariais - FACE, Universidade de Brasília, Brasília.

Gonçalves, R. S., De Medeiros, O. R., Gonçalves, A. de O. (2012) Social disclosure das empresas brasileiras de capital aberto: uma análise qualitativa das ações em programas sociais externos no período de 2005 a 2009. Revista Universo Contábil, 8, 97-118.

Gray, R., Javad, M., Power, D. M., Sinclair, C. D. (2001) Social and environmental disclosure and corporate characteristics: a research note and extension. Journal of Business Finances \& Accounting, 28(3), 327-356, April/May.

Hammond, K., Miles, S.(2004) Assessing quality assessment of corporate social reporting: UK perspectives. Accounting Forum, 28, 61-79.

Haydel, B.F. (1989) A administração estratégica de programas de responsabilidade social em empresas multinacionais: percepções da alta diretoria. Revista de Administração de Empresas, 29(3), 5-29, jul./set.

Heal, G.(2004) Corporate social responsibility - an economic and financial framework. Recuperado em: Dec., 2004, de: 〈http://papers.ssrn.com/sol3/papers.cfm?abstract_id=642762〉.

Hillman, A.J., Keim, G.D. (2001) Shareholder value, stakeholder management, and social issues: what's bottom line? Strategic Management Journal, 22, 125-139.

Jensen, M. C.(2003) A theory of the firm: governance, residual claims, and organizational forms. Cambridge: Harvard University Press. 
Jensen, M. C.(2001) Value maximization, stakeholder theory, and the corporate objective function. Journal of Applied Corporate Finance, Fall.

Jensen, R.E., Campfield, W. L., Frank, W.G., Luoma, G.A., Manes, R.P., Oliver, B.L., Onsi, M., Francis, M. (1972) Report of the committee on measures of effectiveness for social programs. The Accounting Review, Supplement to Volume XLVII, 47, 337-396.

Jones, M. T. The institutional determinants of social responsibility. Journal of Business Ethics. Netherlands: Kluwer Academic Publishers. 20, 163-179.

Kpmg Internacional. (2008) KPMG Internacional Survey of Corporate Responsibility Reporting 2008. Recuperado em: 02 ago.2009, de://<kpmg.com>.

La Porta, R. et al.(1998) Law and finance. The Journal of Political Economy, 106(6), 1113-1155.

MacArthur, J. B.(1996) An investigation into the influence of cultural factors in the international lobbyng of the international accounting standards committee: the case of E32, comparability of financial statements. The International Journal of Accounting, 31(2), 231-237.

Machado, M. R. (2010) As informações sociais e ambientais evidenciadas nos relatórios anuais das empresas: a percepção dos usuários. 159 f. Tese (Doutorado) - Faculdade de Economia, Administração e Contabilidade, Universidade de São Paulo, São Paulo.

Machado Filho, C.A.P., Zylbersztajn, D. (2003) Responsabilidade social corporativa e a criação de valor para as organizações. Faculdade de Economia, Administração e Contabilidade da Universidade de São Paulo, Série de Working Papers, Working Paper n.03/024. Recuperado em: 31 mar.2010, de://www.ead.fea.usp.br/wpapers>.

Milani Filho, M. A. F.(2008) Responsabilidade social e investimento social privado: entre o discurso e a evidenciação. Revista Contabilidade e Finanças, São Paulo, 19(47), 89-101, mai./ago.

McWilliams, A., Siegel, D.S.(2001) Corporate social responsibility: a theory of the firm perspective. The Academy of Management Review, 26(1), 117-127, jan.

Murcia, F. D. R., Santos, A. dos.(2009) Fatores determinantes do nível de disclosure voluntário das companhias abertas no Brasil. REPeC - Revista de Educação e Pesquisa em Contabilidade, 3(2), art.4, 72-95, mai-ago.

Oliveira, M. C., De Luca, M. M. M., Ponte, V. M. R., Pontes Junior, J.E.(2009) Divulgação de informações sociais por empresas brasileiras segundo os indicadores de responsabilidade social corporativa da ONU. Rev. contab. finanç.[online], 20(51), 116-132.

Peliano, A,M.T.M et al.(2002) A iniciativa privada e o espírito público: um retrato da ação social das empresas no Brasil. Brasília: Ipea.

Peliano, A.M.T.M (coord.) et al.(2006) A iniciativa privada e o espírito público: a evolução da ação social das empresas privadas no Brasil. Brasília: Ipea.

Ponte, V. M. R., Oliveira, M. C., Moura, H., Carmo, R. C. A.R. (2007) Análise das práticas de evidenciação de informações obrigatórias, não-obrigatórias e avançadas nas demonstrações 
contábeis das sociedades anônimas no Brasil: um estudo comparativo dos exercícios de 2002 e 2005. Cont. Fin. USP, São Paulo, 18(45), 50-62, set./dez.

Porter, M.E., Kramer, M.R.(2002) The competitive advantage of corporate philanthropy. Harvard Business Review, Dec.

Ramanathan, K. V.(1976) Toward a theory of corporate social accounting. The Accounting Review, Sarasota, 51(3), 516-528, Jul.

Reverte, C.(2008) Determinants of corporate social responsibility disclosure ratings by spanish listed firms. Journal of Business Ethics, 88, 351-366.

Riahi-Belkaoui, A., Karpik, P. G.(1988) Determinants of the corporate decision to disclosure social information. Accounting, Auditing and Accountability Journal, 1(1), 36-51, Dec.

Ribeiro, M. de S., Martins, E. (1993) A informação como instrumento de contribuição da Contabilidade para a compatibilização no desenvolvimento econômico e a preservação do meio ambiente. Caderno de Estudos Fipecafi, São Paulo, 9, 31-40.

Richardson, J. R. et al.(1999) Pesquisa social: métodos e técnicas. São Paulo: Atlas.

Richardson, A. J., Welker, M. (2001) Social disclosure, financial disclosure and the cost capital of equity capital. Accounting Organizations and Society, 26, 597-616.

Roberts, R.W.(1992) Determinants of corporate social responsibility disclosure: An application of stakeholder theory. Accounting, Organizations and Society, 17(6), 595-612, ago.

Rogers, P.(2006) Governança corporativa, mercado de capitais e crescimento econômico no Brasil. 146 f. Dissertação (Mestrado) - Faculdade de Gestão e Negócios, Universidade Federal de Uberlândia, Uberlândia.

Saiia, D.H., Carroll, A.B., Buchholtz, A.K.(2003) Philanthopry as strategy: when corporate charity "begins at home". Business \& Society, 42(2), 169-201, Jun.

Silveira, A. D. M. da, Yoshinaga, C. E., Borba, P. da R. F.(2005) Crítica à teoria dos stakeholders como função-objetivo corporativa. Caderno de Pesquisas em Administração, São Paulo, 12(1), 3342 , jan./mar.

Silveira, A. de M.da.(2002) Governança corporativa, desempenho e valor da empresa no Brasil. 165 f. Dissertação (Mestrado) - Faculdade de Economia, Administração e Contabilidade, Universidade de São Paulo, São Paulo.

Simnett, R., Vanstraelen, A., Chua, W.F.(2009) Assurance on sustainability reports: an international comparison. The Accounting Review, 84(3), 937-967.

Smith, J. van der L., Adhikari, A., Tondkar, R. H.(2005) Exploring differences in social disclosure internationally: a stakeholder perspective. Journal of Accounting and Public Policy, 24, 123-151.

Soihet, E.(2002) Índice de controle de capitais: uma análise da legislação e dos determinantes do fluxo de capital no Brasil no período 1990 - 2000. 96 f. Dissertação (Mestrado) - EPGE - Escola de Pós-graduação em Economia, Fundação Getúlio Vargas, Rio de Janeiro. 
Sternberg, E.(1999) The stakeholder concept: a mistaken doctrine. foundation for business responsibilities, issue paper,(4) november Recuperado em: 21 jun.2007, de: www.ssrn.com/abstract=263144>.

Sundaram, A. K., Inkpen, A.C.(2001) The corporate objective revisited. Thunderbird School of Management Working Paper, out. Recuperado em: 20 out.2011, de: http://papers.ssrn.com/sol3/papers.cfm?abstract_id=293219.

Vanstraelen, A., Zarzeski, M. T., Robb, S. W. G.(2003) Corporate nonfinancial disclosure practices and financial analyst forecast ability across three european countries. Journal of International Financial Management and Accounting, 14(3).

Vaz, A. C., Gonçalves, R. S., Niyama, J. K., Gonçalves, A. O.(2010) Análise comparativa sobre informações voluntárias divulgadas: o social disclosure das empresas latino-americanas listadas na Nyse. Revista de Educação e Pesquisa em Contabilidade - RePEC, 4, 38-59.

Vieira, S. P., Mendes, A. G. S. T.(2006) Governança corporativa: uma análise de sua evolução e impactos no mercado de capitais brasileiro. Revista Organizações em Contexto, São Paulo, 2(3), 4867 , jan./jun.

${ }^{\mathrm{i}} \mathrm{O}$ conceito atribuído para programa social ou projeto social neste artigo está alinhado ao conceito proposto por Jensen et. al. (1972, p.339) no qual "[...] social program is a plan of action, an experiment introduced into society for the purpose of producing a change in the status of the society or some of its members".

${ }^{i i}$ A firm cannot maximize value if it ignores the interest of its stakeholders.

Apêndice A - Lista das empresas analisadas

\begin{tabular}{|l|l|l|l|l|}
\hline Empresa & Empresa & Empresa & Empresa & Empresa \\
\hline Açúcar Guarani & Basf & Dow & Mahle & Tim Celular \\
\hline Aes Sul & Bunge Alimentos & Duke Energy & Medley & Toyota \\
\hline Alcoa & Cargill & Elektro & Moto Honda & Tractebel Energia \\
\hline Amanco & Carrefour & Embratel & Nextel & V\&M \\
\hline Ambev & Ceg & Escelsa & Roche & Wal-Mart \\
\hline Ampla & Cenibra & Heineken Brasil & Siemens & Whirlpool \\
\hline Anglo American & Coelce & Innova & Souza Cruz & White Martins \\
\hline Arcelor Mittal & Comgás & International Paper & Syngenta & \\
\hline Arno Panex & Cteep & Johnson \& Johnson & Telefônica - Telesp & \\
\hline Bandeirante & Dixie Toga & Kimberly-Clark & Tenaris Confab & \\
\hline
\end{tabular}

Data da submissão: 13/07/2012

Data da publicação: 30/08/2013 